\title{
Organophosphorus Compounds Poisoning: Picture in Rangpur Medical College Hospital, Bangladesh
}

\author{
Sarkar DN ${ }^{1}$, Hossain $\mathrm{MI}^{2}$, Ahmed $\mathrm{M}^{3}$, Shaheduzzaman $\mathrm{AKM}^{4}$, Mohammad $\mathrm{N}^{5}$
}

\begin{abstract}
Organophosphorus compounds (OPC) poisoning is a major public health problem in low and middle income countries. The incidence varies from country to country depending on easy availability of poison, socio-economic condition and educational background of the people.
\end{abstract}

This study aimed to determine the frequency, outcome and aetiological aspect of OPC poisoning patient admitted in Rangpur medical college hospital.

It was a cross sectional study carried out in the department of Medicine, Rangpur medical college hospital from $1^{\text {st }}$ December 2011 to $30^{\text {th }}$ November, 2012.

During the study period a total of 703 patients have been studied. The most of the patients were between the age of 1840 years $(91.9 \%)$, male $(51.6 \%)$, married $(71.3 \%)$ and from rural areas (67.8\%). People of different occupations were involved in OPC poisoning, house-wives were the maximum (33.6\%) followed by farmers (31.7\%). 92\% cases were suicidal and $8 \%$ accidental. Familial disharmony was the prime cause $(92.3 \%)$ of suicidal motive. $88 \%$ of the patients were survived and $5 \%$ died.

OPC poisoning is an important health care problem in our country. Improved awareness, restricting availability and banning more toxic organophosphorus compounds will reduce the incidence of $O P C$ poisoning.

\section{Introduction}

Acute poisoning is a major public health problem in low and middle income countries. The poisoning agents involved in our country are different because the social structure, economic status, educational level, awareness of our people and availability of drugs are different from developed countries. Bangladesh is a developing country. The society here is agricultural based. Eighty percent of population is

1. Devendra Nath Sarkar, MCPS, MD, FCCP, FRSM, FACP Professor, Department of Medicine Rangpur Medical College \& Hospital, Rangpur

2. Corresponding Author : Md. Ismail Hossain MBBS OSD, Directorate General of Health Services Deputed in Bangabandhu Sheikh Mujib Medical University, Dhaka email-drrussel27@gmail.com

3. Mainuddinin Ahmed MBBS OSD, Directorate General of Health Services Deputed in Bangabandhu Sheikh Mujib Medical University, Dhaka

4. A.K.M Shaheduzzaman FCPS, MD Assistant Professor, Department of Medicine Rangpur Medical College \& Hospital, Rangpur

5. Nur Mohammad MBBS Medical Officer, UHC Hatibandha, Lalmonirhat dependent on agriculture directly or indirectly. Pesticides are very easily available here. One of them, organophosphorus compound are widely used as insecticides in agricultural sector by farmers for control of insect vectors.

In China and South-east Asia pesticides account for about 300000 suicides each year ${ }^{1}$. Another study suggested that each year worldwide there is 3 million acute poisoning with 2,20,000 deaths. ${ }^{2}$ Much of this burden is borne by developing countries where more than $80 \%$ of cases are fatal pesticide poisoning related hospitalization ${ }^{3}$. Whole over the world acute poisoning is a very common medico-social problem. The agents vary from country to country depending on easy availability of poison, socio-economic condition and educational background of the people. In tropical countries organophosphorus compounds are the commonly used agent ${ }^{4}$. Among different types of poisoning, self poisoning is most common.

In Bangladesh poisoning is an important health problem causing around 2000 deaths per year ${ }^{5}$. Self poisoning constitutes more than half of the total poisoning cases admitted in hospital ${ }^{6}$. Most of poisoning have no strong reason for taking poison. Many have family disharmony, frustration, gain attention or get revenge. Mental illness is sometimes proposed for a background of poisoning. Although reducing accessibility to pesticides will decrease poisoning and deaths, socio-economic and cultural factors must also be addressed to make a real difference. OPC poisoning in a country like Bangladesh is not only a public health problem but also related to economics and culture. There is great need to enhance stress on prevention of poisoning. A coordinated and comprehensive response is needed to make any impact.

\section{Materials And Methods}

All cases of OPC patient aged 18 years and above from $1^{\text {st }}$ December 2011 to $30^{\text {th }}$ November, 2012, who was admitted in Rangpur medical college hospital, were included in this 12-month cross sectional study. Selection criteria for the patients consist of: (1) Physicians made clinical diagnosis of OPC poisoning (2) Age of 18 years or above and both sexes.

\section{Statistical Analysis}

Data was analyzed using SPSS 16 statistical package. A cross sectional analysis was done on all variables to obtain a frequency distribution. The mean $\pm \mathrm{SD}$ and ranges were calculated for quantitative variables. Continuous variables were compared by the Student $t$ test. Proportions were analyzed with the chi-square test or 2-tailed Fisher's exact test as appropriate. A $P$ value of 0.05 or less was considered statistically significant. 


\section{Results}

During the study period a total of 703 patients of both sexes were studied, male was slightly more than the female $(51.6 \%$ vs $48.4 \%)$. Minimum and maximum age of the study population was 18 years and 64 years respectively. Table I showing the socio-demographic characteristics of the study population.

Table I: Socio-demographic characteristics of the study population $(n=703)$

\begin{tabular}{lccc}
\hline \multicolumn{1}{c}{ Variable } & Frequency & Percent & P value * \\
\hline Age & & & \\
18-40 years & 646 & $91.9 \%$ & \\
41-60 years & 50 & $7 \%$ & $0.000^{\mathrm{s}}$ \\
$\quad>60$ years & 7 & $1 \%$ & \\
Sex & & & \\
Male & 363 & $51.6 \%$ & \\
Female & 257 & $48.4 \%$ & $.332^{\mathrm{ns}}$ \\
Marital status & & & \\
Married & 502 & $71.45 \%$ & \\
Unmarried & 201 & $28.55 \%$ & $0.000^{\mathrm{s}}$ \\
Educational status & & & \\
Primary & & & \\
Secondary & 251 & $35.7 \%$ & \\
Higher & 336 & $47.8 \%$ & \\
secondary & 76 & $10.8 \%$ & \\
Graduate and & 09 & $2.5 \%$ & \\
above & 31 & $5.75 \%$ & \\
Illiterate & & & \\
Occupation & & & \\
Service & 22 & $3.2 \%$ & \\
Farmer & 223 & $31.7 \%$ & \\
Student & 147 & $20.9 \%$ & \\
Housewife & 236 & $33.6 \%$ & \\
Business & 54 & $7.65 \%$ & \\
$\quad$ Others & 21 & $2.9 \%$ & \\
\hline Residence & & & \\
$\quad$ Rural & 477 & $67.8 \%$ & \\
$\quad$ Urban & 226 & $32.2 \%$ & \\
\hline
\end{tabular}

NS= not significant, $S=$ significant

Analysis of all the variables have shown that $<40$ years age, married, male sex, people of rural area and educational level below secondary were more involve in OPC poisoning. People of different occupations presented with history of acute poisoning but housewives (33.6\%) were the maximum.

Table II: Showing the motive of different OPC poisoning.

\begin{tabular}{cccc}
\hline Variable & Frequency & Percent & Pvalue* $^{*}$ \\
\hline Suicidal & 648 & $92.2 \%$ & \\
Accidental & 55 & $7.8 \%$ & $0.000^{\mathrm{s}}$
\end{tabular}

Chisquare test was done to see the significance of difference. $\mathrm{S}=$ significant

Accidental poisoning cases occurred during spraying in the field, contaminated pond water, household water and in some cases patient suffering from psychiatric illness accidently took the drugs.

Suicidal tendency was more in male $(53.01 \%)$ than female (46.99\%) and maximum (645) of them are 18-40 years age group.

Table III: Showing the causes of suicidal attempt.

\begin{tabular}{|c|c|c|c|}
\hline Variable & Frequency & Percent & Pvalue* \\
\hline $\begin{array}{l}\text { Familial } \\
\text { disharmony }\end{array}$ & 778 & $92.3 \%$ & \\
\hline $\begin{array}{c}\text { Failed in } \\
\text { examination }\end{array}$ & 17 & $2.1 \%$ & $0.000^{\mathrm{s}}$ \\
\hline $\begin{array}{l}\text { Economical } \\
\text { loss }\end{array}$ & 14 & $1.7 \%$ & \\
\hline $\begin{array}{l}\text { Chronic } \\
\text { illness }\end{array}$ & 31 & $3.7 \%$ & \\
\hline Others & 3 & $0.35 \%$ & \\
\hline
\end{tabular}

*Chisquare test was done to see the significance of difference. $\mathrm{S}=$ significant

Pre-hospital treatments of the poisoning cases were attempted to induce vomiting by applying bitter or dirty things in mouth.

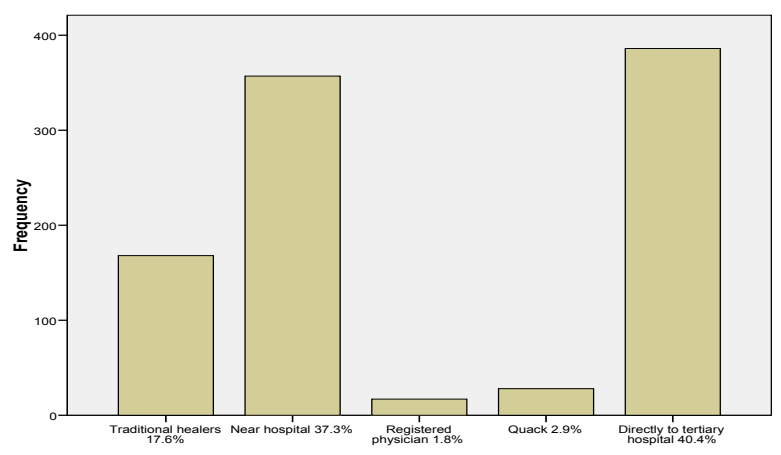

$\mathrm{P}$ value $0.000^{\mathrm{s}}$

Figure: I showing pre-hospital management strategy after acute poisoning

Gastric lavage was given in the entire patient before admission into indoor. In hospital most of the patients received supportive treatments and OPC cases atropine and/ or pralidoxime was given. Total 51 (5.34\%) patients died. Among the death cases 27 were male and 24 were female; 38 from rural areas and 13 from urban areas.

\section{Discussion}

OPC poisoning is an important medical emergency. Management of these critically ill patients will greatly improve if the common causes of poisoning are properly defined $^{7}$. In this study male was slightly higher than the female1.064:1, Males dominated in a study done in tertiary care hospital in Karnataka, India where male to female ${ }^{8}$ ratio was $3: 1$. However, some other studies have shown that males are marginally higher compared to females ${ }^{9,10}$. A similar picture was found in another study by Rahaman MM, Khan GK, et al. where male female ratio was 1.6:1. This high 
proportion of poisoning among males might be due to change in the lifestyle and cultural patterns in this area. In this study, age of the majority of the poisoning cases was between 1840 years $(91.9 \%)$. In another study majority $(61.7 \%)$ was between 12- and 29-year age group. Similar findings were observed in other studies ${ }^{11}$. Married people $(71.3 \%)$ were observed more than unmarried in OPC poisoning in this study. A study on 2003 in rural India also showed that $63 \%$ victims of OPC poisoning were married $^{12}$. By occupation housewife $(33.6 \%)$ were the maximum followed by farmer $(31.7 \%)$ and student $(20.9 \%)$. This findings show similarities with findings of organophosphorus poisoning patients studied in Chittagong Medical College Hospital, where 25.8\% were house wife, $14 \%$ farmers, $16.1 \%$ students ${ }^{13}$.

Motive of poisoning in this study was suicidal $(92.2 \%)$, in another study it was $78.78 \%$. Maximum reported cause of suicidal attempt was familial disharmony (92.3\%). Male sex, age group between 18-40 and patients from rural area were more involve in suicidal attempt. The WHO reports that pesticides are now the most common method of suicide worldwide. ${ }^{14}$ One study showed over half of all hospital admissions for self-harm to a General Hospital in Rio de Janeiro had taken pesticides ${ }^{15}$. Mortality rate was $5.3 \%$ and $5.2 \%$ leave hospital without permission and few cases $(1.9 \%)$ were referred to higher center. This differs with different studies where mortality rate was high. A study has shown that, mortality rate with acute poisoning was $16.4 \%$ mainly due to organophosphorus compounds. Low mortality rate in this study probably was due to increased awareness of the people and reaching to hospital faster. Poisoning cases are neglected one, these patients are kept in floor and veranda of very busy medicine unit, and there is no separate unit for management of poisoning cases. As there was no support of mechanical ventilation, respiratory failure was tried to manage with endotracheal tube intubation and AMBU bag respiration by patient's relative. Lack of trained doctors, nurses and limited resources have a bad impact to manage the OPC poisoning patients. Hospitals facilities, logistics and staffs could not cope with such type of huge number patients.

OPC poisoning is an important health care problem in our country. The character of poisoning has been changed over time for different reasons. Though mortality rate is not so high, it has an impact on social and family environment. Death cases of organophosphorus poisoning were associated with severe symptoms and higher lethality. Poisoning patients are very much neglected. It is clear that in poisoning there is a specific reason behind this. So doctors, nurses, paramedics and other stuff should be empathetized to these patients and proper counseling is necessary along with treatment to prevent further occurrence. Measures like restricting availability and banning more toxic organophosphorus compounds and drugs may help to prevent poisoning. By increasing facilities of chemical identification of poisoning cases and availability of more effective and specific treatment, fatality of OPC poisoning may fall in hospital.

\section{Acknowledgement}

We are grateful to Dr. Md.Golam Mostofa, Director of Rangpur Medical College Hospital for allowing us to collect the data of poisoning patients. We also like to thank all the Nurses caring for the tetanus patients and to all the staffs working in Medical Record section of this hospital for their cordial helduring this study.

\section{References}

1. In: Colledge NR, Walker B R, Ralstone S H Davidson's Principles $\&$ Practice of Medicine, $21^{\text {th }}$ edition, Churchill Livingstone Elsevier,2010; 203-207.

2. Minton NA, Murray VSG. A review of organophosphorus poisoning. Med toxicol1988;3:350-357.

3. Tafury J, Roberts J. Organophosphorus poisoning. Ann Emerg Med. 1987;16:193-202.

4. Jeyaratnam J. Health problems of pesticide usage in third world. British Journal of Int Med. 1985;42:505-506.

5. Bangladesh Health Bulletin (2001) UMIS, Director General of Health Services (2001), Dhaka.

6. Rahaman MM, Khan GK. clinical patten of acute poisoning in medical units of Dhaka Medical College Hospital. J Dhaka Medical Coll 1994;3:1-5.

7. Singh S, Sharma BK, Wahi PL. Spectrum of acute poisoning in adults. $\mathrm{J}$ Assoc Physicians India 1984;32:561-3.

8. Unnikrishnan B, Singh B, Rajeev A. Trends of acute poisoning in South Karnataka. Kathmandu Univ Med J (KUMJ) 2005;3:149-54.

9. Dash SK, Aluri SR, Mohanty MK, Patnaik KK, Mohanty S. Sociodemographic profile of poisoning cases. JIAFM 2005;27:133-8.

10. Srivastava A, Peshin SS, Kaleekal T, Gupta SK. An epidemiological study of poisoning cases reported to the National Poisons Information Centre, All India Institute of Medical Sciences, New Delhi. Hum Exp Toxicol 2005;24:279- 85 .

11. Das RK. Epidemiology of Insecticide poisoning at A.I.I.M.S Emergency Services and role of its detection by gas liquid chromatography in diagnosis. Medico update 2007;7:49-60.

12. Tsoi WF, Kok LP. Self poisoning in Singapore- main causative factors. Singapore Med J 1981;22:284-7.

13. Hoque MF. Incidence and Clinical Pattern of Acute Poisoning in a District Hospital. Bang Med J, Jan-Apr 1986,15:13-17.

14. Bertolote JM, Fleischmann A, Butchart A, Besbelli N: Suicide, suicide attempts and pesticides: a major hidden public health problem.Bull World Health Organ 2006 , $84: 260$.

15. Werneck GL, Hasselmann MH, Phebo LB, Vieira DE, Gomes VL: [Suicide attempts recorded at a general hospital in Rio de Janeiro, Brazil.]. Saude Publica 2006 , 22:2201-2206. 